\title{
High-risk Behaviors: A Discriminant Analysis of Individual Factors in Students
}

\author{
Rahim Farzin ${ }^{1}$, Nadereh Sohrabi Shekofti ${ }^{* *}$, Maryam Kouroshnia ${ }^{3}$ \\ 1. PhD Student in Educational Psychology, Department of Educational Psychology, Marvdasht Branch, Islamic Azad \\ University, Marvdasht, Iran \\ 2. Assistant Professor, Department of Educational Psychology, Marvdasht Branch, Islamic Azad University, Marvdasht, \\ Iran. \\ 3. Assistant Professor, Department of Educational Psychology, Marvdasht Branch, Islamic Azad University, Marvdasht, Iran \\ * Corresponding author's Email: Sohrabi_sh2006@yahoo.com
}

\begin{abstract}
The aim of this study was to explain the group membership model using discriminant analysis for high school students with high risk behaviors based on individual factors. The research method was correlational because the relationship between individual variables with high-risk behaviors in students was investigated. The statistical population was all high school male and female students who were studying in schools of Shiraz in the 2019 academic year. Sampling of this research was done by accessible method. The participants included 120 students who were matched in terms of age, educational level, parents' degree and relative socio-economic status and were divided into two groups. The first group included 30 boys and 30 girls with high-risk behaviors and the second group (the control group) included 60 participants (30 males and 30 females). To collect data, the scale of Iranian adolescent risk behaviors (IARS), Zuckerman Sensation Seeking Scale, Garnfsky cognitive emotion regulation questionnaire, and Luthans psychological capital questionnaire were used. For statistical analysis, discriminant analysis method was used. The results indicated that the equation of discriminant analysis has the power to classify normal students and students with highrisk behavior based on individual variables (cognitive regulation of emotion, sensation seeking, and psychological capital). Also, the discriminant analysis equation had the power to classify normal students and students with high-risk behavior male students but in female students did not have any significant power.
\end{abstract}

Keywords: High risk behaviors, High school students, Individual variables, Discriminant analysis

\section{Introduction}

Adolescence and youth are important periods of development. This is a period between childhood and adulthood when a person prepares to enter adulthood. During this period, the person feels independent and somehow, the supervision and involvement of parents is reduced (OECD \& Organization, 2020). This group of people do not follow their parents like children and do not have the necessary wisdom and awareness like adults. As a result, they are more likely to engage in behaviors that are dangerous to themselves and others and endanger their future (Sanci, Webb, \& Hocking, 2018). These behaviors, called high-risk behaviors, include a variety of behaviors, including smoking, drugs and alcohol use, high-risk sexual behaviors, reckless driving, running away from home or school, and street fights. Highrisk behavior refers to any behavior that could threaten physical or mental health now or in the future (Kotchick, Shaffer, Miller, \& Forehand, 2001).

Committing high-risk behaviors can have detrimental consequences for the individual and society, overshadowing the individual's life, and may alter and distort his / her life path. High-risk behaviors are the most important factor in endangering the health of society (Soori, Poormanafi, Rashidpour, \& 
Khalghi, 2020). Nouruzi and Amiri (2016) indicated that high risk behaviors, life events, birth order and number of children play a significant role in forecasting and explaining mental health of adolescence. Numerous individual factors cause adolescents to commit high-risk behaviors. One of these factors is sensation seeking, which is defined in terms of the willingness and actions of taking risks to accomplish different and highly stimulating experiences as well as the desire to take physical, social, legal, and financial risks (Marvin Zuckerman, 2007b). Marvin Zuckerman (2007b) believes that this phenomenon is an intriguing trait that is defined by the need for diverse, novel and complex feelings and experiences and the desire for physical and social risk due to such experiences.

People with high sensation seeking are more likely to engage in risky behaviors. In this regard, emotion management is also effective in doing or avoiding the high-risk behaviors. Cognitive strategies in emotion regulation include rumination, acceptance, self-blame, positive refocusing, refocus on planning, positive reappraisal, putting into perspective, catastrophizing, and blaming others (Garnefski \& Kraaij, 2007). Individuals who displayed high levels of neuroticism and a tendency to use maladaptive cognitive emotional regulation strategies are more likely to engage in risky behaviors (Auerbach, Claro, Abela, Zhu, \& Yao, 2010).

Another individual factor is psychological capital, which is rooted in positive organizational behavior and positive psychology. Psychological capital is a hybrid and interconnected structure that includes four perceptual-cognitive components, namely hope, optimism, self-efficacy, and resilience (Luthans, Luthans, \& Luthans, 2004). People with high psychological capital indicated positive attitude and high emotional management. As a result, they are less likely to engage in behaviors that are detrimental to themselves and others. Adolescences who have higher personal resiliency (a component of psychological capital) report less frequent risk behaviors (Prince-Embury, 2015). Previous studies revealed that several individual factors have been confirmed in predicting high-risk behaviors in adolescents (Chen, Dunne, \& Han, 2006; Claro, Boulanger, \& Shaw, 2015; Lipowski, Lipowska, Jochimek, \& Krokosz, 2016; Palacios, 2018; Safa, Valiee, Fazel Darbandi, \& Aghajani, 2020; Marvin Zuckerman, 2007a). Accordingly, the present study aimed to explain the group membership model of high school students with high-risk behaviors based on individual indicators.

\section{Material and Methods}

The research method was correlational, and discriminant analysis was used to examine the group membership of high school students in high risk behaviors based on individual factors. The statistical population of the study consisted of male and female high school students who were studying in schools of Shiraz in the 2019 academic year. 120 male and female high school students were selected as the sample of the study by accessible sampling method, which was divided into two groups: the first group consisted of 30 boys and 30 girls, who had high-risk behaviors (as an experimental group) and the second group 30 girls and 30 boys (as a control group). Both of groups were matched in terms of age, educational level, parents' education and socio-economic status. 
The Iranian Adolescents' Risk Behavior Scale (IARS), the Zuckerman sensation-seeking Scale, the Luthans Psychological Capital Questionnaire, and the Garnefski Cognitive Emotion Regulation Questionnaire were used to collect data.

To measure the level of risk in adolescents in different dimensions (tendency to drugs, tendency to alcohol, tendency to smoking, tendency to violence, tendency to sex and sexual behavior, tendency to have sex with the opposite sex, tendency to dangerous driving), the scale of high-risk behaviors Iranian Adolescents (IARS) which included 38 questions was used. The scoring method is based on a fivedegree Likert scale in a range from very disagree to a very agree in the range of 1-5 scores. The minimum score is 38 and the maximum is 190. A score between 38 and 76 indicates low risk, a score between 76 and 114 indicates a moderate risk, and a score above 114 indicates a high risk. In the study of Zadeh Mohammadi, Ahmadabadi, and Heidari (2011), the construct validity of this scale was evaluated. Exploratory factor analysis with principal components showed that this questionnaire is a sevendimensional scale, which explains $64.84 \%$ of the variance of risk-taking. Cronbach's alpha for the whole scale was .94 and for its subscales ranged from .74 to .93 , which indicates an appropriate reliability vale. In the current study, the validity of the scale was confirmed by confirmatory factor analysis and its reliability was estimated to be .82 by Cronbach's alpha method.

Sensation seeking variable including four sub-scales of Thrill and Adventure Seeking (TAS); Disinhibition (Dis); Experience Seeking (ES); and Boredom Susceptibility (BS) were measured by the Zuckerman Sensation Seeking Scale (Marvin Zuckerman, 2007b). For each factor, ten items are considered. Each item has two-part, the first part, expresses the amount of emotion of the person and the second part, is in reverse. Mahvishirazi (2008) has reported the validity and reliability of this scale as .78 and .80 , respectively. The validity of the scale in the present study was confirmed by confirmatory factor analysis and its reliability was obtained by Cronbach's alpha method as .76.

The Luthans 24-item psychological capital questionnaire (Luthans, Avey, Clapp-Smith, \& Li, 2008) was used to assess psychological capital. The participants answered each question on a 6-point Likert scale (from strongly disagree to strongly agree). A higher score indicates more psychological capital. In Bahadori Khosroshahi, Hashemi Nosratabad, and Babapour Kheirodin (2012) research, the reliability of the questionnaire using Cronbach's alpha was .85. The validity of the scale in the current study was confirmed by confirmatory factor analysis and its reliability was calculated by Cronbach's alpha to be .79 .

Garnefski and Kraaij (2007) scale was used to measure cognitive emotion regulation strategies. This scale is a 36-item instrument that has a five-point Likert response scale from 1 (never) to 5 (always). This questionnaire consists of 9 subscales of rumination, acceptance, self-blame, positive refocusing, refocus on planning, positive reappraisal, putting into perspective, catastrophizing, and blaming others. The Persian version of this scale has been validated by Samani and Sadeghi (2010). The alpha coefficient for the subscales of this questionnaire was reported by Garnefski and Kraaij (2007) in the range of .71 to .81 . The validity of the scale in the present study was confirmed by confirmatory factor analysis. Its reliability was .84 by Cronbach's alpha method. 
Discriminant analysis was used to test the research hypotheses. It should be noted that the data were analyzed by SPSS software version 19 .

\section{Results}

The mean and standard deviation of the studied variables in the whole sample, in male students and in female students are presented in Tables 1 to 3 .

Table 1. Mean and standard deviation of the research variables in the total sample

\begin{tabular}{|c|c|c|c|c|c|}
\hline \multirow[t]{2}{*}{ Variable } & \multirow[t]{2}{*}{ Components } & \multicolumn{2}{|c|}{ Normal students } & \multicolumn{2}{|c|}{ High risk behaviors students } \\
\hline & & Mean & SD & Mean & $\mathrm{SD}$ \\
\hline \multirow{2}{*}{$\begin{array}{l}\text { Cognitive emotional } \\
\text { regulation }\end{array}$} & Cognitive regulation of positive emotion & 49.65 & 9.17 & 50.85 & 9.77 \\
\hline & Cognitive regulation of negative emotion & 62.65 & 10.83 & 64.85 & 11.48 \\
\hline \multirow[t]{4}{*}{ Sensation seeking } & Experience Seeking & 13.88 & 1.78 & 14.28 & 1.48 \\
\hline & Thrill and Adventure Seeking & 14.11 & 1.38 & 14.37 & 1.58 \\
\hline & Boredom Susceptibility & 15.76 & 1.87 & 14.50 & 1.88 \\
\hline & Disinhibition & 15.44 & 1.56 & 15.21 & 1.76 \\
\hline \multirow[t]{4}{*}{ Psychological capital } & Self efficacy & 24.59 & 7.28 & 25.95 & 6.31 \\
\hline & Hope & 24.41 & 7.72 & 25.26 & 5.34 \\
\hline & Resiliency & 22.54 & 6.16 & 23.26 & 5.19 \\
\hline & Optimism & 22.97 & 5.62 & 24.08 & 4.16 \\
\hline \multirow[t]{7}{*}{ High risk behaviors } & Drug addiction & 10.45 & 3.58 & 13.77 & 5.51 \\
\hline & Tendency to alcohol & 8.93 & 3.43 & 14.42 & 6.71 \\
\hline & Tendency to smoke & 6.34 & 2.60 & 9.23 & 5.24 \\
\hline & Tendency to violence & 9.88 & 4.01 & 14.03 & 4.86 \\
\hline & Tendency to relationship and sexual behavior & 6.84 & 3.60 & 10.78 & 5.02 \\
\hline & $\begin{array}{l}\text { Tendency to have a relationship with the } \\
\text { opposite sex }\end{array}$ & 8.63 & 3.82 & 13.67 & 4.21 \\
\hline & Dangerous driving tendencies & 12.84 & 5.06 & 19.39 & 5.40 \\
\hline
\end{tabular}

Table 2. Mean and standard deviation of the research variables in the male students

\begin{tabular}{|c|c|c|c|c|c|}
\hline \multirow[t]{2}{*}{ Variable } & \multirow[t]{2}{*}{ Components } & \multicolumn{2}{|c|}{ Normal students } & \multicolumn{2}{|c|}{ High risk behaviors students } \\
\hline & & Mean & SD & Mean & SD \\
\hline \multirow{2}{*}{$\begin{array}{l}\text { Cognitive emotional } \\
\text { regulation }\end{array}$} & Cognitive regulation of positive emotion & 50.48 & 8.52 & 50.90 & 9.98 \\
\hline & Cognitive regulation of negative emotion & 64.96 & 8.31 & 64.39 & 11.01 \\
\hline \multirow[t]{4}{*}{ Sensation seeking } & Experience Seeking & 13.50 & 1.66 & 14.39 & 1.60 \\
\hline & Thrill and Adventure Seeking & 14.04 & 1.42 & 14.21 & 1.63 \\
\hline & Boredom Susceptibility & 15.95 & 1.96 & 14.59 & 1.85 \\
\hline & Disinhibition & 15.41 & 1.55 & 15.23 & 1.72 \\
\hline \multirow[t]{4}{*}{ Psychological capital } & Self efficacy & 26.80 & 4.63 & 26.13 & 5.66 \\
\hline & Hope & 27.12 & 5.07 & 24.59 & 5.51 \\
\hline & Resiliency & 24.44 & 5.30 & 22.95 & 5.36 \\
\hline & Optimism & 24.48 & 4.40 & 23.84 & 4.38 \\
\hline \multirow[t]{5}{*}{ High risk behaviors } & Drug addiction & 10.72 & 3.37 & 13.15 & 4.36 \\
\hline & Tendency to alcohol & 9.76 & 3.76 & 15.40 & 6.45 \\
\hline & Tendency to smoke & 6.80 & 2.98 & 8.72 & 4.78 \\
\hline & Tendency to violence & 10.92 & 4.06 & 14.09 & 4.86 \\
\hline & Tendency to relationship and sexual behavior & 7.88 & 3.96 & 11.50 & 5.04 \\
\hline
\end{tabular}




\begin{tabular}{|c|c|c|c|c|c|}
\hline \multirow{2}{*}{} & $\begin{array}{c}\text { Tendency to have a relationship with the } \\
\text { opposite sex }\end{array}$ & 9.80 & 4.30 & 14.18 & 4.12 \\
\cline { 2 - 6 } & Dangerous driving tendencies & 13.76 & 5.44 & 18.90 & 5.55 \\
\hline
\end{tabular}

Table 3. Mean and standard deviation of the research variables in the female students

\begin{tabular}{|c|c|c|c|c|c|}
\hline \multirow[t]{2}{*}{ Variable } & \multirow[t]{2}{*}{ Components } & \multicolumn{2}{|c|}{ Normal students } & \multicolumn{2}{|c|}{ High risk behaviors students } \\
\hline & & Mean & SD & Mean & SD \\
\hline \multirow{2}{*}{$\begin{array}{c}\text { Cognitive emotional } \\
\text { regulation }\end{array}$} & Cognitive regulation of positive emotion & 48.57 & 10.09 & 53.31 & 9.58 \\
\hline & Cognitive regulation of negative emotion & 59.63 & 13.08 & $\mathbf{7 0 . 8 7}$ & 12.06 \\
\hline \multirow[t]{4}{*}{ Sensation seeking } & Experience Seeking & 14.36 & 1.86 & 14.12 & 1.14 \\
\hline & Thrill and Adventure Seeking & 14.21 & 1.35 & 14.87 & 1.54 \\
\hline & Boredom Susceptibility & 15.52 & 1.77 & 14.87 & 2.21 \\
\hline & Disinhibition & 15.47 & 1.61 & 15.50 & 1.50 \\
\hline \multirow[t]{4}{*}{ Psychological capital } & Self efficacy & 21.68 & 9.07 & 26.50 & 6.17 \\
\hline & Hope & 20.66 & 9.24 & 27.50 & 5.24 \\
\hline & Resiliency & 20.05 & 6.45 & 25.68 & 4.90 \\
\hline & Optimism & 21 & 6.51 & 25.51 & 4.03 \\
\hline \multirow[t]{7}{*}{ High risk behaviors } & Drug addiction & 10.10 & 3.91 & 15.35 & 7.69 \\
\hline & Tendency to alcohol & 7.84 & 2.67 & 11.88 & 6.90 \\
\hline & Tendency to smoke & 5.73 & 1.91 & 10.52 & 6.27 \\
\hline & Tendency to violence & 8.52 & 3.61 & 13.88 & 5.01 \\
\hline & Tendency to relationship and sexual behavior & 5.47 & 2.56 & 8.94 & 4.61 \\
\hline & $\begin{array}{l}\text { Tendency to have a relationship with the } \\
\text { opposite sex }\end{array}$ & 7.10 & 2.42 & 12.35 & 4.25 \\
\hline & Dangerous driving tendencies & 11.63 & 4.37 & 20.64 & 4.91 \\
\hline
\end{tabular}

In order to test the research hypotheses, the discriminant analysis test was used and its results are presented in table 4. In the table 4, the M-Box values and eigenvalues of the discriminant analysis test in the total sample, male and female students are indicated. According to the results, the M-Box index is significant for the total sample and male students, so it can be said that the equation of discriminant analysis in the total sample and male students has the power to discriminate normal students from students with High-risk behavior based on individual variables. Table 5 indicates the rate of predictive power to discriminate normal students from students with high-risk behavior in the total sample, female and male students.

Table 4. Results of the discriminant analysis test in total sample, male and female students

\begin{tabular}{|c|c|c|c|c|c|}
\hline Index & M box value & Eigenvalue & Df1 & Df2 & $\mathrm{p}$ \\
\hline \multirow{3}{*}{ Value } & 739.12 & 1.31 & 378 & 20438.89 & .001 \\
\cline { 2 - 7 } & .397 & .385 & 1 & 3072 & .535 \\
\cline { 2 - 7 } & 404.22 & 1.10 & 210 & 6057.93 & .047 \\
\hline
\end{tabular}

Table 5. The predictive power of discriminant analysis test in total sample, male and female students

\begin{tabular}{|c|c|c|c|c|c|}
\hline Index & Group & Eigenvalue & Chi-square & df \\
\hline \multirow{2}{*}{ Value } & Total & 1.46 & 70.95 & 27 & .001 \\
\cline { 2 - 7 } & Female & 2.06 & 24.66 & 20 & .215 \\
\hline
\end{tabular}




\begin{tabular}{|l|l|l|l|l|l|}
\hline & Male & 10.18 & 37.56 & 20 & .010 \\
\hline
\end{tabular}

According to Table 5, the discriminant analysis equation has power to discriminate normal students from students with high-risk behavior based on individual variables. Also, the value of Wilks' lambda index is equal to 0.405. In female students, the discriminant analysis equation has no power to discriminate normal students from students with high-risk behavior based on individual variables. Also, the value of Wilks' lambda index is equal to 0.326. In male students, the discriminant analysis equation has a significant discriminant power to distinguish normal students from high-risk students based on individual variables. Based on the findings, the discriminant analysis equation has discriminated $85.84 \%$ of the subjects based on individual variables.

\section{Discussion}

The aim of this study was to discriminate high-risk students from high-risk students based on individual indicators (cognitive emotion regulation, sensation seeking, and psychological capital). The results indicated that the equation of discriminant analysis has the power to discriminate normal students from students with high risk behavior based on individual variables in the total sample and male students. This finding is consistent with the findings of Miron Zuckerman (1979) who found that $74 \%$ of people who were highly aroused were using one or more of the drugs. This rate was $32 \%$ in people with low sensation seeking. Miron Zuckerman (1979) believes that gender and age are the variables that are most associated with sensation seeking. Zhang, Zhang, and Shang (2016) also showed that there is a positive correlation between adolescents' high arousal and high-risk behaviors such as reckless driving and sexual acts without contraceptives. Borjali, Aazami, and Chopan (2016) indicated in a research entitled the effectiveness of training emotion regulation strategies on reducing sensation seeking in drug addicts that emotion regulation training reduces experience seeking and boredom. Also, the results of Behboodi and Ahmadi Tahoor Soltani (2018) revealed that the educational package of substance abuse prevention is effective in reducing high-risk behaviors. Keykhosrovani, Dehghani, and Dehghani (2017) examined the relationship between self-regulation and moral intelligence with addiction readiness through sensation seeking and showed that sensation seeking has a mediating role in relation of self-regulation, moral intelligence and addiction readiness.

In general, it can be concluded that in the present study, individual indicators (cognitive regulation of emotion, sensation seeking and psychological capital) have the power to discriminate students with highrisk behavior from students without high-risk behavior. Each of the indicators of cognitive regulation of emotion, sensation seeking and psychological capital alone has a positive effect on the discrimination between normal students and students with high-risk behavior in total and male sample. Based on empirical evidence and research literature, we explain the inability of the discriminant analysis equation to discriminate between female students with high-risk behavior and female students without high-risk behavior as follows: 
A) Lack of psychological freedom among female students in expressing psychological issues and negative personality traits. Among girls, the tendency to express negative emotions is much less than boys, and expressing this trait is associated with more shame and shyness than boys.

B) Having more empathy by girls, which makes the two groups of female students with and without high-risk behaviors (compared to boys), has a higher homogeneity and the discriminant power of discriminant analysis tests reaches its minimum efficiency.

C) The student's introversion causes him/her to refuse to express her/his inner states and characteristics to others. The problem of introversion has been identified as a disturbing variable in this study, which is significantly more common among girls than boys. Research by Yousefi, Taymoori, Azadi, and Khasi (2016) showed that $92 \%$ of girls have an introverted personality type. Therefore, girls refuse to express their psychological states and characteristics due to high introversion.

The present study has been associated with some limitations that should be considered in generalizing the results. The limitation of the sample to high school students in Shiraz and the use of a questionnaire to measure research variables has been the most important limitations of this study. Based on this, it is suggested that in future researches, the subject of the present research be repeated in other cities of the country and in other age groups. It is suggested that the findings of the present study, along with the explanation of the results, be provided to teachers, professors and university professors in the form of a booklet or article. It is also suggested that educational counseling centers use the findings of this research in counseling students and solving their academic and psychological problems.

Conflict of interest: The authors stated no conflict of interest in the study.

Financial sponsor: The authors acknowledge that they have not received any financial support for all stages of the study, writing and publication of the paper.

Acknowledgment: We appreciate all the participants of the study as well as all those participating in the implementation of this project.

\section{References}

Auerbach, R. P., Claro, A., Abela, J. R., Zhu, X., \& Yao, S. (2010). Understanding risky behavior engagement amongst Chinese adolescents. Cognitive therapy and research, 34(2), 159-167.

Bahadori Khosroshahi, J., Hashemi Nosratabad, T., \& Babapour Kheirodin, J. (2012). The Relationship Of Psychological Capital With Social Capitalamong Students Of Tabriz University. JOURNAL OF RESEARCH AND HEALTH, 2(1), 63-71. 
Behboodi, M., \& Ahmadi Tahoor Soltani, M. (2018). The Effectiveness Of Drug Use And Acquired Immune Deficiency Syndrome (Aids) Prevention Package On Drug Use And High Risk Behaviors Reduction Among College Students. JOURNAL OF HEALTH EDUCATION AND HEALTH PROMOTION, 6(2), 114-124.

Borjali, A., Aazami, Y., \& Chopan, H. (2016). The Effectiveness Of Emotion Regulation Strategies Training On Reducing Of Sensation Seeking In Drug- Dependent Persons. Journal of clinical psychology, 8(2 (30)), 3342.

Chen, J., Dunne, M. P., \& Han, P. (2006). Child sexual abuse in Henan province, China: associations with sadness, suicidality, and risk behaviors among adolescent girls. Journal of Adolescent Health, 38(5), 544-549.

Claro, A., Boulanger, M.-M., \& Shaw, S. R. (2015). Targeting Vulnerabilities to Risky Behavior: an Intervention for Promoting Adaptive Emotion Regulation in Adolescents. Contemporary School Psychology, 19(4), 330339. doi:10.1007/s40688-015-0063-9

Garnefski, N., \& Kraaij, V. (2007). The cognitive emotion regulation questionnaire. European Journal of Psychological Assessment, 23(3), 141-149.

Keykhosrovani, M., Dehghani, A., \& Dehghani, Y. (2017). The Causal Relation Of Self-Regulation And Moral Intelligence With Addiction Potential Through The Mediating Role Of Sensation-Seeking Among Female Students. Research on Addiction, 11(43), 249-266.

Kotchick, B. A., Shaffer, A., Miller, K. S., \& Forehand, R. (2001). Adolescent sexual risk behavior: A multisystem perspective. Clinical psychology review, 21(4), 493-519.

Lipowski, M., Lipowska, M., Jochimek, M., \& Krokosz, D. (2016). Resiliency as a factor protecting youths from risky behaviour: Moderating effects of gender and sport. European journal of sport science, 16(2), 246-255.

Luthans, F., Avey, J. B., Clapp-Smith, R., \& Li, W. (2008). More evidence on the value of Chinese workers' psychological capital: A potentially unlimited competitive resource? The International Journal of Human Resource Management, 19(5), 818-827.

Luthans, F., Luthans, K. W., \& Luthans, B. C. (2004). Positive psychological capital: Beyond human and social capital. Business Horizons, 47(1), 45-50. doi:10.1016/j.bushor.2003.11.007

Mahvishirazi, M. (2008). Reliability, Validity and Manner of Zuckerman Sensation-SeekingCulture-Based Scale. Daneshvar Raftar, 15(28), 35-48.

Nouruzi, K., \& Amiri, M. (2016). Relationship of high risk behaviors and negative life events with mental health of female students in high schools. Iranian journal of public health, 45(6), 833-834.

OECD, \& Organization, W. H. (2020). Adolescent health: World Health Organization

Palacios, J. (2018). Interplay between sensation seeking and risky alcohol drinking in Mexican adolescents: An structural modeling equation approach. International journal of psychological research, 11(2), 19-26.

Prince-Embury, S. (2015). Risk behavior and personal resiliency in adolescents. Canadian Journal of School Psychology, 30(3), 209-217.

Safa, A., Valiee, S., Fazel Darbandi, A., \& Aghajani, M. (2020). Risky behaviors and sensation-seeking in adolescence: a descriptive correlational study. Comprehensive child and adolescent nursing, 43(4), 260-273.

Samani, S., \& Sadeghi, L. (2010). Psychometric Properties Of The Cognitive Emotion Regulation Questionnaire. JOURNAL OF PSYCHOLOGICAL MODELS AND METHODS, 1(1), 51-62. 
Sanci, L., Webb, M., \& Hocking, J. (2018). Risk-taking behaviour in adolescents. Australian journal of general practice, 47(12), 829-834.

Soori, A., Poormanafi, A., Rashidpour, B., \& Khalghi, N. (2020). The Role of Lifestyle in Predicting High-Risk Behavior of Tehran's Thugs. Quarterly Journal of Criminal \& Intelligence Researches, 14(4 (56) \#r001046), $-$

Yousefi, F., Taymoori, P., Azadi, N. A., \& Khasi, B. (2016). Investigate Frequency The Type of Personality (Introverts And Extroverts) and Excitement (Stability, Neurosis And Psychosis) Kurdistan University of Medical Sciences Student. Zanko Journal of Medical Sciences, 17(52), 18-27.

Zadeh Mohammadi, A., Ahmadabadi, Z., \& Heidari, M. (2011). Construction and assessment of psychometric features of Iranian adolescents risk-taking scale. Iranian Journal of Psychiatry and Clinical Psychology, 17(3), 218-225.

Zhang, L., Zhang, C., \& Shang, L. (2016). Sensation-seeking and domain-specific risk-taking behavior among adolescents: Risk perceptions and expected benefits as mediators. Personality and Individual Differences, 101, 299-305.

Zuckerman, M. (1979). Attribution of success and failure revisited, or: The motivational bias is alive and well in attribution theory. Journal of personality, 47(2), 245-287.

Zuckerman, M. (2007a). Sensation seeking and risky behavior: American Psychological Association.

Zuckerman, M. (2007b). The sensation seeking scale V (SSS-V): Still reliable and valid. Personality and Individual Differences, 43(5), 1303-1305. 